TPeriodica Polytechnica Civil Engineering

OnlineFirst (2018) paper 11806

https://doi.org/10.3311/PPci.11806

Creative Commons Attribution (i)

RESEARCH ARTICLE

\section{Reliability Analysis of Rock Slope Excavation Considering the Stochasticity and Finite Persistence of Wedges}

\author{
Guilin Wang ${ }^{1,2}$, Fan Sun ${ }^{1,2^{*}}$, and Qiuyuan Tang ${ }^{3}$
}

Received 10 December 2017; Revised 11 January 2018; Accepted 15 January 2018

\begin{abstract}
With a focus on wedge failure during rock slope excavation and considering stochasticity and finite persistence based on a stochastic structural-plane network simulation and Lajtai's rock resistance criteria, we present a simplified method combined with binary particle swarm optimization (BPSO) to calculate the shear strength of $3 D$ rock masses. The probabilities of rock slope failure under excavation surfaces of various sizes were obtained using the Monte Carlo method. These probabilities can provide a theoretical basis for determining excavation stability. The approach was applied to a rock slope excavation project in Chongqing, China, and yielded satisfactory results.
\end{abstract}

\section{Keywords}

wedge failure, rock slope excavation, failure probability, network simulation, rock bridge, BPSO

\footnotetext{
1 Key Laboratory of New Technology for Construction of Cities in Mountain Area (Chongqing University)

Ministry of Education

Chongqing 400045, China

2 School of Civil Engineering

Chongqing University

Chongqing 400045, China

3 China Coal Technology \& Engineering Group Corp.

Chongqing Engineering Co., Ltd.

Chongqing 400045, China

* Corresponding author, email: 1319469487@qq.com
}

\section{Introduction}

Wedge failure is one of the most common mode of rock slope failure. In most previous engineering applications, the approach to analyzing rock slope stability has been to simply study known wedges, which have a definite shape, size, and location and good persistence, to obtain a stability coefficient. The stereographic projection method [1], limit equilibrium method [1], plastic limit analysis method [2], [3], [4], and other new methods [5], [6], [7] are all based on mature theories, are well developed, and are widely used in engineering.

However, excavation differs in that there are not yet any good methods for conducting a specific investigation of all structural planes within a rock slope; thus, the wedges exposed in an excavation surface are stochastic and finite persistent. In addition, excavation surfaces are dynamically changing. All of these factors create unpredictability and risk regarding rock slope stability that cannot be addressed using existing methods. Thus, we need a new approach that takes into account the stochasticity and finite persistence of wedges within a rock slope to dynamically analyze the stability of a rock slope excavation, estimate the risk, and guide the construction.

Recently, many scholars have presented the concept of stochastic structural-plane network simulation and reliability analysis based on statistics and probability theory. These techniques can be used to describe the spatial distribution of structural planes statistically and to quantify the uncertainty. These two methods have been applied successfully in rock mechanics. For example, after Baecher presented a circular model of structural planes in 1977 [8], many scholars applied it to geotechnical engineering [9]-[12]. Einstein et al. used the model to analyze the effect of discontinuity persistence on rock slope stability [14]. In addition, ever since probability theory was applied to slope engineering in the 1970s, great achievements have been made, including the analysis of rock slope stability using probability theory by McMahon et al. [15]-[20]. All of these methods effectively address stochasticity in rock slope stability analysis.

The effect of finite persistence on rock slope stability cannot be ignored because in practice larger wedges tend to be more stable due to the rock bridge between structural planes. Lajtai 
divided the failure modes of discontinuous rock in direct shear into three types [23], [24], and this system has great theoretical value and practical significance. Afterwards, many scholars studied the propagation and coalescence of structural planes based on uniaxial and biaxial compressive tests [14], [25]-[32]. All of these methods provide a theoretical basis for addressing finite persistence in rock slope stability analysis.

However, the stochasticity and finite persistence of wedges make the process of stability analysis too complex for application to practical problems. Thus, this article presents a simplified method to applying the above methods efficiently to rock slope excavations combined with BPSO to calculate the shear strength of 3D rock masses and obtain the probabilities of rock slope failure behind excavation surfaces of various sizes using the Monte Carlo method.

\section{Stochastic simulation of a structural plane network}

To analyze rock slope stability taking into account the stochasticity and finite persistence of wedges, a network model that simulates the structural planes must be established first. Although the distribution of structural planes is unpredictable and complex, they still follow statistical rules. Thus, we can use data collected in the field to develop a probability function for each set of structural planes and generate a certain number of stochastic structural planes using the Monte Carlo method to create a $3 \mathrm{D}$ network model that is statistically similar to a real set of structural planes.

In this method, there are several assumptions:

1. The structural plane has the shape of a round disk [8]; this shape has been found to approximate the true shapes of structural planes in most cases [33].

2. The structural planes in each set comply with a uniform probability distribution, and each structural plane has mutually independent variables [34].

3. The center of each structural plane is uniformly distributed in the 3D model space [35],[36].

Based on these assumptions, the radius and volume density can be calculated using Eqs. 1 and 2 [9]:

$$
\begin{gathered}
f_{r}(r)=\frac{\pi}{2} f\left(\frac{\pi}{2} r\right) . \\
\lambda_{d}=2 \pi \lambda_{v} \int_{0}^{+\infty} R \int_{R}^{+\infty} f_{r}(r) d r d R=\frac{1}{\bar{d}} .
\end{gathered}
$$

Where $r$ is the radius, $l$ is the trace length, $f_{r}(r)$ is the density function of the radius, $f(l)$ is the density function of the trace length, $\bar{d}$ is the average spacing of the structural planes, $\lambda_{d}$ is the linear density, and $\lambda_{v}$ is the volume density.

Fig. 1 shows a 3D stochastic model of a structural plane network with a volume measuring 10 meters $\times 10$ meters $\times 10$ meters and containing three sets of structural planes and a $2 \mathrm{D}$ model of one section through the network.

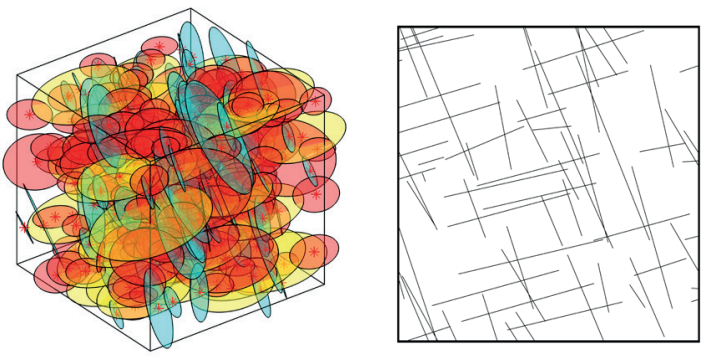

Fig. 1 Stochastic model of structural plane network

\section{Lajtai's rock resistance criteria}

Lajtai studied the strength of intact rock bridges in direct shear tests [23],[24] and found three failure modes at different normal stresses $\sigma_{a}$. These modes consist of tensile failure at low stress, shear failure at high stress, and crushing of rock bridge sat still higher stress, followed by shearing at residual stress values.

Lajtai also found that in most slope stability analyses, the range of $\sigma_{a}$ is generally less than the critical value of $2 \operatorname{ctan} \varphi$, where $c$ is the cohesion of the rock and $\varphi$ is the internal friction angle. Therefore, the tensile failure mode is more common under general conditions, thus the shear failure mode is neglected in the following discussion.

In the tensile failure mode, with increasing shear force, the minimum principal stress $\sigma_{3}$ reaches the tensile strength of the intact rock $\sigma_{t}$ first and causes several tensile cracks (also called wing cracks) to form along the direction of maximum principal stress at high angles to the direction of sliding. Simultaneous with the appearance of these cracks, the peak shear resistance in the sliding direction is attained. Afterwards, shear cracks along the direction of sliding appear, followed by shear failure of the intact rock (Fig. 2). The peak shear resistance $\tau_{a}$ and the angle between the wing cracks and the direction of sliding $\theta$ can be calculated as follows [23], [24]:

$$
\begin{gathered}
\theta=\frac{1}{2} \arctan \frac{2 \tau_{a}}{\sigma_{a}} . \\
\tau_{a}=\sqrt{\sigma_{t}\left(\sigma_{t}+\sigma_{a}\right)} .
\end{gathered}
$$

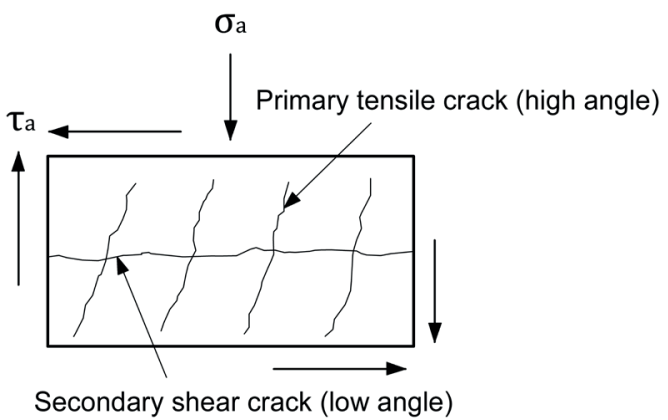

Fig. 2 Tensile failure in direct shear

Based on Lajtai's model, Einstein et al. [14] summarized structural plane coalescence in two cases (Fig. 3). In high angle transitions $(\omega>\theta)$ between two structural planes, a continuous 
wing crack develops directly between two planes without secondary shear cracks. In low angle transitions $(\omega>\theta)$, wing cracks and shear cracks lead to coalescence of the two planes.
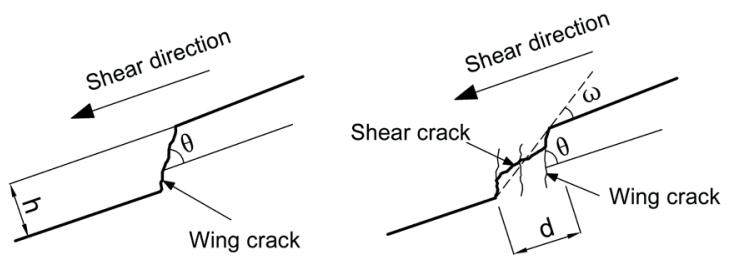

Fig. 3 Structural plane coalescence

\section{Shear strengths of $2 \mathrm{D}$ rock masses}

\subsection{Shear strengths of structural planes}

Fig. 4 shows a structural plane of angle $\alpha$ in a unit length of rock mass where $T$ is the lateral shear force, $W$ is the vertical force, $S$ is the shear resistance of the structural plane, and $N$ is the normal force on the structural plane. According to the Mohr-Coulomb failure criterion, when failure occurs, the force-balance equation can be written as follows:

$$
T \cos \alpha-W \sin \alpha=(T \sin \alpha+W \cos \alpha) \tan \varphi+\frac{c}{\cos \alpha} .
$$

Substituting $\sigma_{n}$ for $W$ and $\tau$ for $T$ in Eq. (5) yields the following equation:

$$
\tau=\sigma_{n} \tan (\alpha+\varphi)+\frac{\cos \varphi}{\cos \alpha \cdot \cos (\alpha+\varphi)} c .
$$

Based on this equation, the shear strength of the structural plane is related not only to the shear strength parameters but also to the angle $\alpha$ [37]. The shear strength increases with increasing values of $\alpha$; when $\alpha$ reaches $90^{\circ}-\varphi$, the shear strength becomes infinite, indicating that shear failure will not occur along this structural plane.

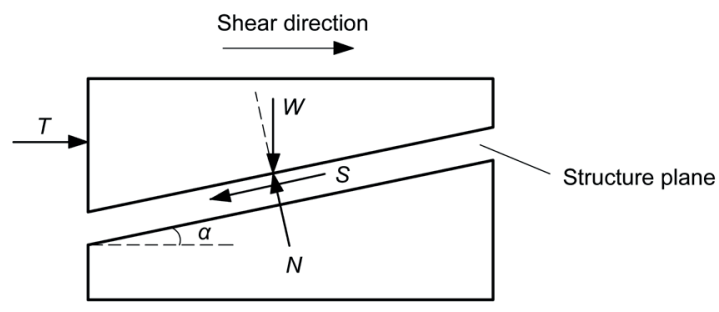

Fig. 4 Force diagram of structural plane in shear

\subsection{Shear strengths of rock bridges}

Based on the research of Shen, Wong, Robet, et al. [25]-[31], we simplified the coalescence of structural planes to four basic types that are convenient for computer analysis (Fig. 5).

For angle transitions in range " $A$ ", the two planes coalesce by way of shear cracks along the direction of sliding. The shear strength of the rock bridges can be calculated as follows:

$$
R_{r}=d \sqrt{\sigma_{t}\left(\sigma_{t}+\sigma_{a}\right)}
$$

For angle transitions in range " $B$ ", the two planes coalesce by way of shear cracks and wing cracks. The shear strength of the rock bridges can be calculated using Eq. 7.
For angle transitions in range " $C$ ", the two planes coalesce directly by way of wing cracks. The shear strength of the bridges can be calculated as follows:

$$
R_{r}=h \sigma_{t} .
$$

For case " $D$ ", there is no contribution to the shear strength from the rock bridge between two intersecting planes.

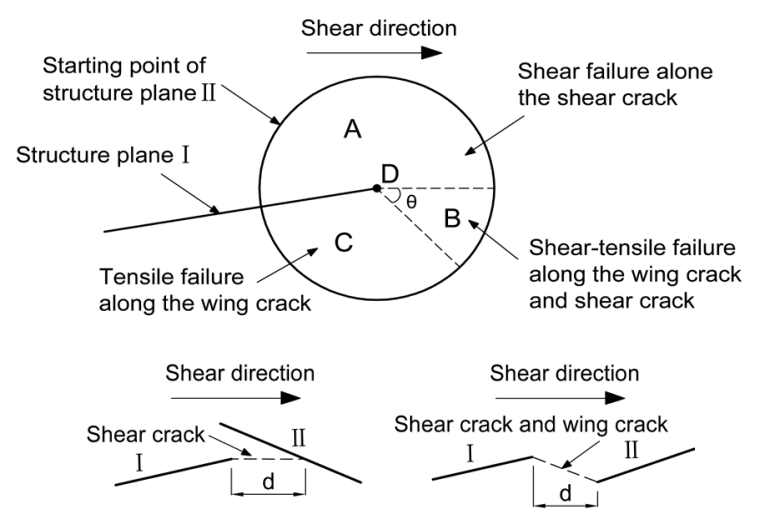

(A)

(B)

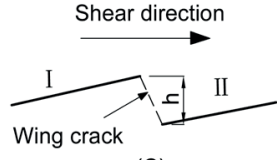

(C)

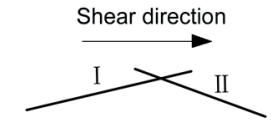

(D)
Fig. 5 Simplified model of structural plane coalescence

\subsection{Minimum shear strength combination}

Thus, the strength of structural planes and rock bridges can be calculated, and by referring to Einstein's definition of joint persistence [14], we can obtain the shear strength and failure path of the rock mass in any direction of shear by determining the minimum shear strength combination of the rock bridges and structural planes. The procedure can be summarized as follows:

1. Build a 3D stochastic model of the structural plane network and a 2D model along one section. Create a shear zone measuring $L \times B$ metres in the 2D model and establish new coordinates in which the sliding direction is parallel to the $\mathrm{x}-\mathrm{y}$ plane and the shear zone is parallel to the $\mathrm{x}-\mathrm{z}$ plane (Fig. 6). Thus, the search range and coordinate system are determined for the next steps.

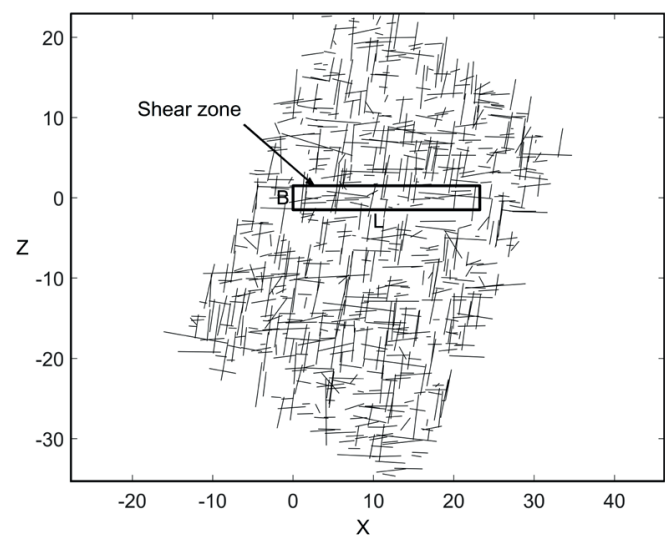

Fig. 6 Shear zone in 2D network model 
2. Find all of the structural plane segments within the range of the shear zone (Fig. 7-a).

3. Separate the high-angle $\left(\alpha \geq 90^{\circ}-\varphi\right)$ structural plane segments from other segments due to their infinite shear strength (Fig. 7-b), although they still can be combined with the tensile cracks (Fig. 7-d, in circle).

4. To simplify the search process, locate every structural plane segment based on a starting point and an ending point according to the shear direction and then sort them based on the positions of their starting points (Fig. 7-c).

5. Separate structural plane segments that intersect with others into several parts defined by their intersections (Fig. 7 -c, in circle).

6 . For each possible combination, determine the coalescence type of every two adjacent structural plane segments in order. Then, calculate the strength of the rock bridges using Eqs.7 and 8 and add the strength of the structural planes obtained from Eq. 6 to obtain the total shear strength.

7. Finding the minimum shear strength combination (Fig. 7-d) yields the shear strength of the rock mass and the failure path within the mass.

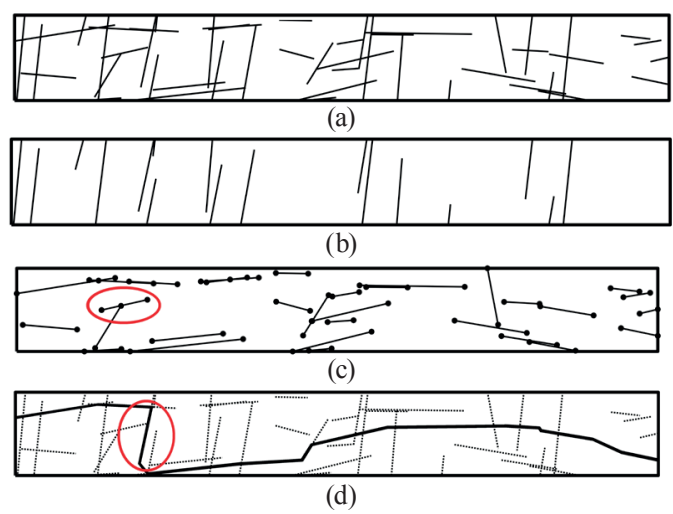

Fig. 7 Search method for minimum shear strength combination

\subsection{Anisotropy and size effect of rock masses in shearing}

The shear strength of the rock mass, obtained as described in section 4.3, is clearly related to the properties of the structural planes and intact rock. The direction and size of the shear zone also affect the shear strength. Therefore, we established a network model of structural plane A using the parameters in Tablel, and shear zones of various directions and sizes were investigated.

As shown in Figure 8, each point on the curve represents the shear strength of a shear zone on a failure plane which has the same strike direction with reference structural plane and tend to slide along its dip direction, the angle between the normal vector of this shear failure plane and the normal vector of preference structural plane is $\Delta \alpha$, which is in a range of $0^{\circ}$ to $360^{\circ}$. Similarly, in Figure 9, each point on the curve stands for the shear strength of a shear zone on a failure plane which has the same dip angle with reference structural plane but different dip directions, the angle between the two dip directions is $\Delta \beta$, which is also in a range of $0^{\circ}$ to $360^{\circ}$. The shear strength is a minimum when $\Delta \alpha$ is $0^{\circ}, 180^{\circ}$ or $360^{\circ}$ and when $\Delta \beta$ is $0^{\circ}$ or $360^{\circ}$, which means that the failure planes are parallel to the preferred structural plane. And the shear strength is a maximum when $\Delta \alpha$ and $\Delta \beta$ are about $90^{\circ}$ or $270^{\circ}$, which means that the normal vector or dip direction of failure planes are perpendicular to the preferred structural plane's.. In other words, the critical shear failure plane is parallel to the preferred structural plane in most cases.

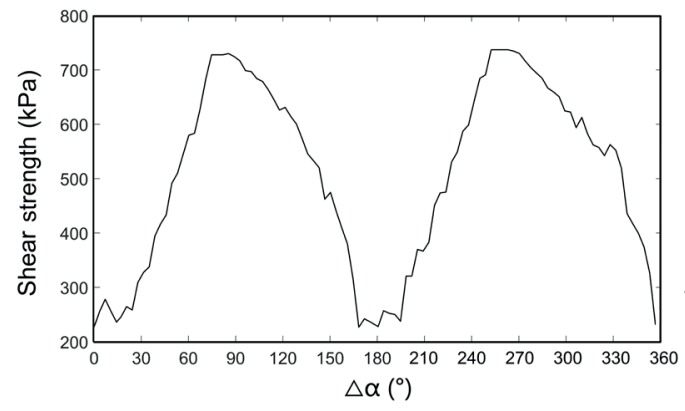

Fig. 8 Shear strength as a function of $\Delta \alpha$

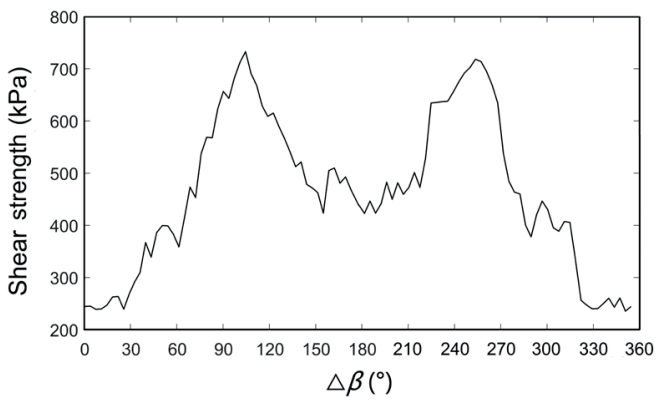

Fig. 9 Shear strength as a function of $\Delta \beta$

Additionally, the shear strength curve can be drawn by changing the width of the shear zones while holding the other conditions constant (Fig. 10). The wider the shear zone, the lower the shear strength, because the combinations are insufficient to yield the minimum strength when the shear zone is narrow. The shear strength remains constant after the width of the shear zone reaches 2 to 3 times the average structural plane spacing, which is $1.37 \mathrm{~m}$ in this case. Therefore, 2 to 3 times the average spacing is taken as the shear zone width in the following analysis.

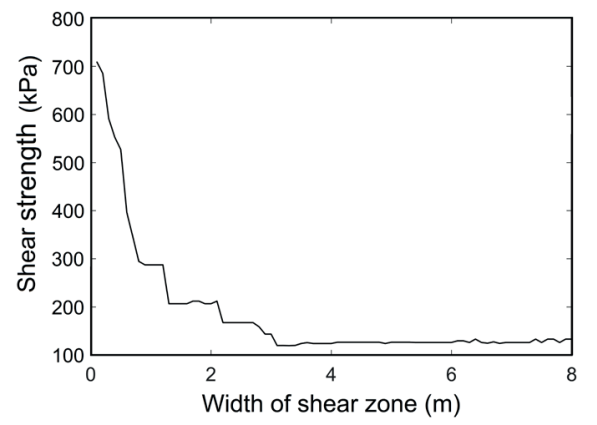

Fig. 10 Shear strength as a function of shear zone width 
In Fig. 11, each point corresponds to a shear zone with a unique length. The variation in shear strength shows a significant size effect: shear strength along short shear zones are all low, indicating that small rock masses can always be completely penetrated by structural planes. As the length of a shear zone increases, the shear strength increases, and it stabilizes at $30 \%$ of the intact rock shear resistance after the shear zone length reaches approximately 10 times the average structural plane radius, which is $1.27 \mathrm{~m}$ in this case. This pattern develops because the proportion of structural planes and rock bridges along the failure path in a large rock mass is relatively constant.

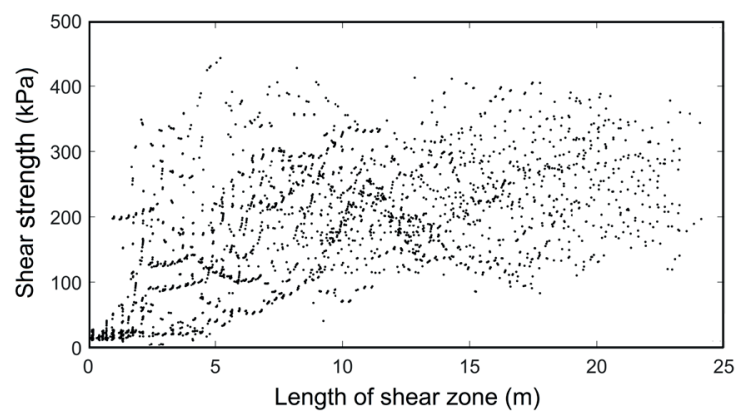

Fig. 11 Shear strength corresponding to various shear zone lengths

\section{Shear strength of 3D rock masses \\ 5.1 Slice methods for 3D shear zones}

However, analyzing the reliability of a rock slope excavation is a $3 \mathrm{D}$ problem, and the assumption in the $2 \mathrm{D}$ method that structural planes are infinite in the third dimension yields lower shear strength.

Following the Swedish slice method of soil slope stability, we can cut the 3D shear zone of a wedge into thin slices along the shear direction (Fig. 12). When the number of slices is sufficiently large, the 3D problem can be converted to 2D problems along each slice, and the shear strength of the 3D shear zone can be calculated by adding the shear strength along all the slices (Eq.9):

$$
R_{3 D}=\sum R_{2 D}^{i} \cdot t_{i} .
$$

Where $R_{3 D}$ is the shear strength of the $3 \mathrm{D}$ shear zone, $R_{2 D}^{i}$ is the shear strength of the $i$-th $2 \mathrm{D}$ slice, and $t_{i}$ is the thickness of the $i$-th slice.

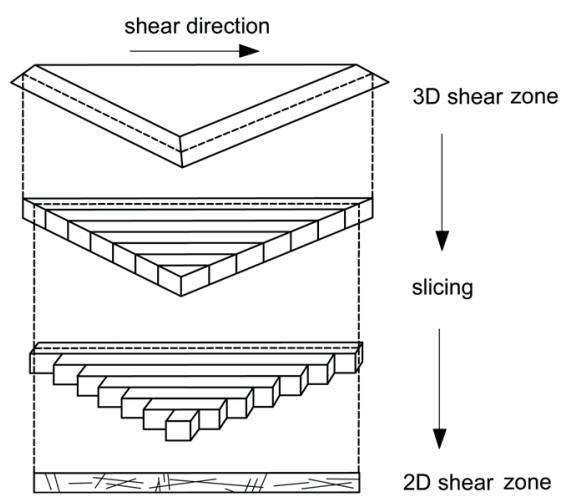

Fig. 12 Slice method applied to a 3D shear zone
In this application of the slice method to a 3D shear zone, the inter-slice force between each two adjacent slices is neglected; the errors caused by this assumption would be small because of the force is an internal force. This assumption that shear strength of all slices reach the maximum simultaneously leads to a higher result, and this assumption that failure of all slices happens along the path of minimum shear strength simultaneously leads to a lower result; fortunately, the two errors are partly counteracted. Nevertheless, this method overcomes the greatest defect of the 2D method in that it takes into account the form and distribution of the structural planes.

\subsection{Search method combined with BPSO}

In $2 \mathrm{D}$ problems, general analytical methods are applied to determine the minimum shear strength combination [38], but in a 3D model with a large number of structural planes, such methods may be inappropriate. Thus, we applied a recently developed artificial intelligence algorithm to solve this problem.

Particle swarm optimization (PSO) simulates the social behavior of organisms such as birds. Each solution is considered a particle in the search space, and each particle has a fitness value. During movement, each particle adjusts its position by changing its velocity according to its own experience and the group's experience, finally moving to the optimal position [39]. There is a discrete binary version (BPSO) of PSO that was introduced by Kennedy and Eberhart in 1997 [40], which can be used for the optimization of discrete variables.

Due to its high speed and its simple algorithm, we applied BPSO to determine the minimum shear strength combination in a $3 \mathrm{D}$ shear zone. For this procedure, the following steps were followed:

1. Define an $n$-dimensional search space in which $n$ is the total number of structural planes in the 3D shear zone. The positions of particles in each dimension are represented by the two discrete binary numbers " 0 " and " 1 "; " 1 " indicates that the structural plane corresponding to the dimension was chosen in the combination, whereas " 0 " indicates that the plane was not.

2. Initialize a population of particles with random positions and velocities in each dimension. Based on the position of each particle, use the methods described in section 5.1 to calculate the shear strength of the chosen combination in the 3D shear zone; this shear strength is the fitness value. Fig. 13 shows a chosen combination in a 3D shear zone.

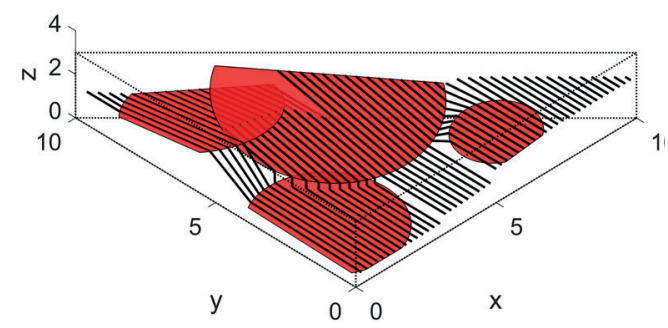

Fig. 13 A combination in a 3D shear zone 
3. For each particle, if the current fitness value is better than its best fitness value, then replace the best position and fitness value with the current position and fitness value. If the current fitness value is better than the group's best fitness value, then replace the group's best position and fitness value with its current position and fitness value.

4. The velocities in BPSO are defined as probabilities; a certain part of a particle's position will change to " 0 " or " 1 ". Each particle is updated using the following equations:

$$
\begin{aligned}
& v^{i j}(t+1)=\omega \cdot v^{i j}(t)+c_{1} \cdot r_{1}^{i j}(t) \cdot\left(x_{\text {pbest }}^{i j}(t)-x^{i j}(t)\right) \\
& +c_{2} \cdot r_{2}^{i j}(t) \cdot\left(x_{g b e s t}^{j}(t)-x^{i j}(t)\right) \\
& x^{i j}(t+1)=\left\{\begin{array}{l}
1 ; r \leq \frac{1}{1+\exp \left(-v^{i j}(t+1)\right)} \\
0 ; r>\frac{1}{1+\exp \left(-v^{i j}(t+1)\right)}
\end{array}\right.
\end{aligned}
$$

where $v^{i j}$ is the velocity of the $i$-th particle in the $j$-th dimension; $x^{i j}(t)$ is the position of the $i$-th particle in the $j$-th dimension; $t$ is the number of updates; $r, r 1$ and $r 2$ are independent random numbers in the range of $[0,1] ; c 1$ and $c 2$ are acceleration parameters, and $w$ is the inertial weight, which can be dynamically changed to adjust the global search capability and local search capability.

Generally, the particle velocities are restricted to a range of $\left[V_{\min }, V_{\max }\right]$ to control excessive roaming of particles outside the search space.

5. The process is then iterated from steps 3 through 5 until a predetermined minimum error is achieved. Finally, the best position representing the minimum shear strength combination and the best fitness value representing the minimum shear strength are obtained.

Fig. 14 shows a search involving 50 particles, approximately 100 iterations and 233 combinations. BPSO is much more efficient than general analytical methods and thereby enables the study of rock slope stability using a large number of 3D network models.

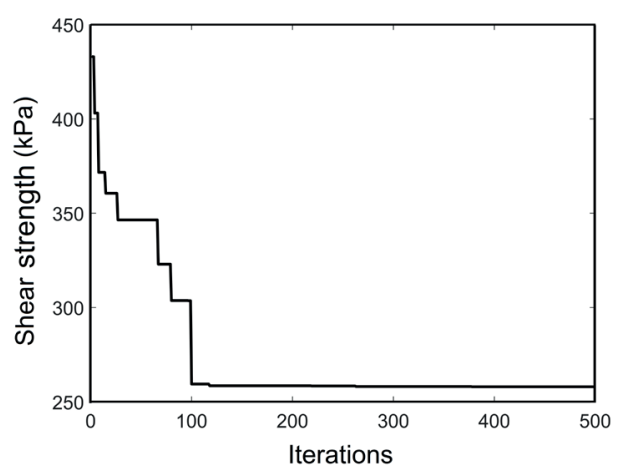

Fig. 14 Search process using BPSO

\section{Probability of rock slope failure during excavation}

The following steps are used to calculate the probability of a rock slope failure involving excavation surfaces of various sizes.

1. Build a stochastic structural plane network model with an excavation surface of a size based on field data.

2. In accordance with the analysis described in section 4.4, for each set of structural planes, define a set of shear planes parallel to the preferred structural plane. The spacing between shear planes can be adjusted to achieve the required precision.

3. Determine the wedges formed by each pair of shear planes exposed in the excavation surface. For each wedge found, model a " $V$ "-shaped 3D shear zone with a certain thickness (usually 2 to 3 times the average structural plane spacing) based on the pair of shear planes (Fig. 15). The direction of shearing is along the intersection line between the planes.

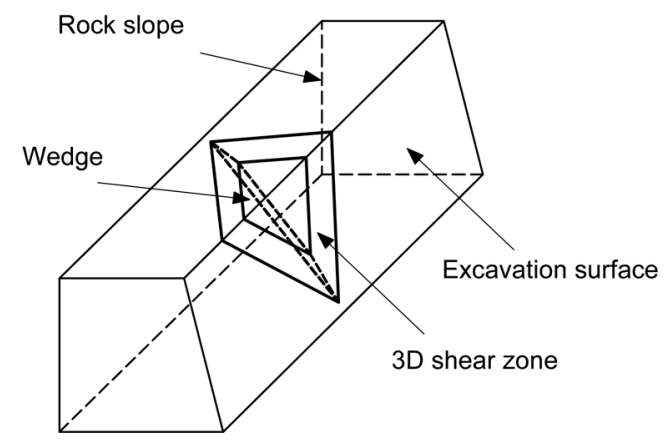

Fig. 15 3D shear zone of the wedge

4. Use the method described in sections 5.1 and 5.2 to calculate the shear strength of the $3 \mathrm{D}$ shear zone under a series of normal stresses $\left(\sigma_{a}\right)$. Thus, a fitted envelope curve can be drawn to obtain the shear strength parameters $c$ and $\varphi$ in accordance with the Mohr-Coulomb criterion.

5. Divide the weight of the wedge into two parts. One is a regular triangular pyramid, and the other is the irregular part overlying the failure path in the 3D shear zones, which can be calculated by partitioning each $2 \mathrm{D}$ slice into a series of vertical parts bounded along their bottom by structural planes or rock bridges (Fig. 16). Thus, the weight of the wedge can be calculated as follows:

$$
W=W_{1}+\gamma_{r} \cdot \sum_{i} \sum_{j} S_{i j} \cdot t_{i} .
$$

Where $W 1$ is the weight of the regular triangular pyramid, $\gamma_{r}$ is the unit weight of the rock, $S_{i j}$ is the area of the $i$-th part in the $j$-th slice, and $t_{i}$ is the thickness of the $i$-th slice.

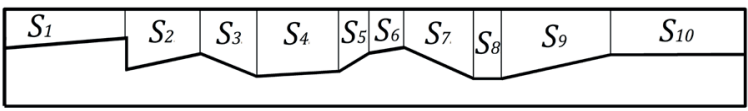

Fig. 16 Partitioning of 3D wedges

6. In accordance with limit equilibrium theory, calculate the stability coefficient of each wedge using the following relationships (Fig. 17): 


$$
\begin{aligned}
& \left\{\begin{array}{l}
N_{1}=\frac{W \cdot \cos \beta_{s} \cdot \cos \omega_{x^{\prime} 2}}{\cos \omega_{x^{\prime} 2} \cdot \cos \omega_{z^{\prime} 1}-\cos \omega_{x^{\prime} 1} \cdot \cos \omega_{z^{\prime} 2}} . \\
N_{2}=\frac{W \cdot \cos \beta_{s} \cdot \cos \omega_{x^{\prime} 1}}{\cos \omega_{x^{\prime} 1} \cdot \cos \omega_{z^{\prime} 2}-\cos \omega_{x^{\prime} 2} \cdot \cos \omega_{z^{\prime} 1}}
\end{array}\right. \\
& K=\frac{N_{1} \cdot \tan \varphi_{1}+N_{2} \cdot \tan \varphi_{2}+c_{1} \cdot A_{1}+c_{2} \cdot A_{2}}{W \cdot \sin \beta_{s}} .
\end{aligned}
$$

Where $W$ is the weight of the wedge; $N_{1}$ and $N_{2}$ are the normal forces on each shear plane; $\beta_{s}$ is the angle of the intersection line; $\omega_{x^{\prime} 1}, \omega_{z^{\prime} 1}, \omega_{x^{\prime} 2}$ and $\omega_{z^{\prime} 2}$ are the angles between the normal forces and the local coordinates; $c_{1}, c_{2}, \varphi_{1}$ and $\varphi_{2}$ are the shear strength parameters of each shear plane; $A_{1}$ and $A_{2}$ are the areas of each shear plane; and $K$ is the stability coefficient.

7. In each network model, take the minimum $K$ of all of the wedges exposed in the excavation surface as the stability coefficient of the entire slope.

8. After a certain number of network models are built, obtain the failure probability $\hat{p}$ using the Monte Carlo method:

$$
\begin{gathered}
M_{i}=\left\{\begin{array}{ll}
1 & K_{i} \leq 1 \\
0 & K_{i}>1
\end{array} .\right. \\
p=\frac{M_{1}+M_{2}+\ldots+M_{n}}{n} .
\end{gathered}
$$

where $K_{i}$ is the stability coefficient of the rock slope in the $i$-th network model and $\mathrm{n}$ is the number of network models.

9. Change the size of the excavation surface, and obtain the failure probability in every case.

\begin{tabular}{|c|c|c|c|c|c|c|c|c|}
\hline \multirow[t]{2}{*}{ Sets } & \multicolumn{3}{|c|}{ Dip angle $\left(^{\circ}\right)$} & \multicolumn{4}{|c|}{$D_{\max }$} & \multirow{2}{*}{$\begin{array}{c}\boldsymbol{D}_{(\boldsymbol{n}, a)} \\
\alpha=0.05\end{array}$} \\
\hline & Distribution & Mean & Variance & Normal & Exponential & Log-normal & Weibull & \\
\hline Bedding surface & Normal & 15 & 2.56 & 0.0743 & 0.8745 & 0.1221 & 1 & 0.1231 \\
\hline Structural plane A & Normal & 67 & 6.64 & 0.1276 & 0.1295 & 0.1632 & 0.9363 & 0.1466 \\
\hline Structural plane B & Normal & 75 & 6.64 & 0.1154 & 0.1937 & 0.0963 & 0.1876 & 0.1662 \\
\hline \multirow[t]{2}{*}{ Sets } & \multicolumn{3}{|c|}{ Dip direction $\left(^{\circ}\right)$} & \multicolumn{4}{|c|}{$D_{\max }$} & $D_{(n, a)}$ \\
\hline & Distribution & Mean & Variance & Normal & Exponential & Log-normal & Weibull & $\alpha=0.05$ \\
\hline Bedding surface & Normal & 300 & 2.56 & 0.0873 & 1 & 0.1348 & 0.1135 & 0.1231 \\
\hline Structural plane A & Normal & 130 & 10.21 & 0.0972 & 0.2175 & 0.1032 & 0.2341 & 0.1466 \\
\hline Structural plane B & Normal & 34 & 3.58 & 0.1327 & 0.9427 & 0.1284 & 1 & 0.1662 \\
\hline \multirow[t]{2}{*}{ Sets } & \multicolumn{3}{|c|}{ Spacing $(m)$} & \multicolumn{4}{|c|}{$D_{\max }$} & $D_{(n, a)}$ \\
\hline & Distribution & Mean & Variance & Normal & Exponential & Log-normal & Weibull & $\alpha=0.05$ \\
\hline Bedding surface & Exponential & 0.67 & 1 & 0.2948 & 0.1037 & 0.1269 & 0.2759 & 0.1231 \\
\hline Structural plane A & Exponential & 0.57 & 0.8 & 0.1385 & 0.1127 & 0.2954 & 0.1396 & 0.1466 \\
\hline Structural plane B & Exponential & 0.84 & 0.5 & 0.4532 & 0.1235 & 1 & 0.9348 & 0.1662 \\
\hline \multirow[t]{2}{*}{ Sets } & \multicolumn{3}{|c|}{ Trace length $(m)$} & \multicolumn{4}{|c|}{$D_{\max }$} & $D_{(n, a)}$ \\
\hline & Distribution & Mean & Variance & Normal & Exponential & Log-normal & Weibull & $\alpha=0.05$ \\
\hline Bedding surface & Exponential & 0.67 & 3 & 0.2537 & 0.0658 & 0.1894 & 0.2371 & 0.1231 \\
\hline Structural plane A & Exponential & 1 & 1 & 0.1654 & 0.1021 & 0.1367 & 0.1569 & 0.1466 \\
\hline Structural plane B & Exponential & 0.67 & 1 & 0.1632 & 0.1176 & 0.1604 & 0.1573 & 0.1662 \\
\hline \multirow[t]{2}{*}{ Sets } & \multicolumn{3}{|c|}{$\mathrm{c}(k P a)$} & \multicolumn{4}{|c|}{$D_{\max }$} & $D_{(n, a)}$ \\
\hline & Distribution & Mean & Variance & Normal & Exponential & Log-normal & Weibull & $\alpha=0.05$ \\
\hline Bedding surface & Normal & 15 & 2.56 & 0.0249 & 0.1535 & 0.1206 & 0.1346 & 0.1231 \\
\hline Structural plane A & Normal & 20 & 5.11 & 0.1233 & 0.9476 & 0.0843 & 1 & 0.1466 \\
\hline Structural plane B & Normal & 20 & 5.11 & 0.1182 & 0.1794 & 0.1569 & 0.1762 & 0.1662 \\
\hline \multirow[t]{2}{*}{ Sets } & \multicolumn{3}{|c|}{$\varphi\left({ }^{\circ}\right)$} & \multicolumn{4}{|c|}{$D_{\max }$} & $D_{(n, a)}$ \\
\hline & Distribution & Mean & Variance & Normal & Exponential & Log-normal & Weibull & $\alpha=0.05$ \\
\hline Bedding surface & Normal & 10 & 1.02 & 0.0471 & 0.1258 & 0.1342 & 0.1158 & 0.1231 \\
\hline Structural plane A & Normal & 12 & 1.54 & 0.0893 & 0.2374 & 0.1449 & 0.1932 & 0.1466 \\
\hline Structural plane B & Normal & 12 & 1.54 & 0.1383 & 0.1428 & 0.1218 & 0.9432 & 0.1662 \\
\hline
\end{tabular}

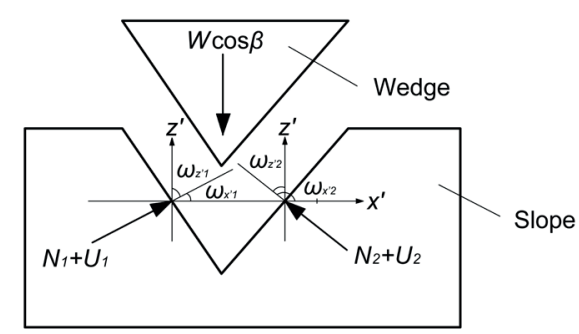

Fig. 17 Limit equilibrium analysis of wedge stability

Table 1 Parameters of structural planes 


\section{Results and discussion}

This approach was applied to a rock slope excavation project in Chongqing, China. Several months earlier, a wedge failure accident had occurred causing 3 deaths and 3 injuries (Fig. 18).
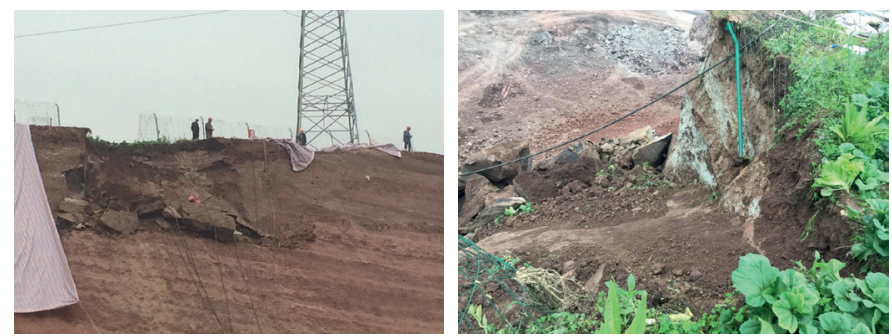

Fig. 18 Wedge failure during excavation

The rock slope is 70 meters long and 21.6 meters tall and has a 3-meter-thick soil layer overlying the slope crest with a weight of $20 \mathrm{kN} / \mathrm{m}^{3}$. The slope gradient is $75^{\circ}$, and the slope direction is azimuth $90^{\circ}$. The bedrock consists mainly of moderately weathered mudstone with a unit weight of $25 \mathrm{kN} / \mathrm{m}^{3}$. The mean tensile strength of the intact rock is $730 \mathrm{kPa}$, and the variance is $90 \mathrm{kPa}$. The rock mass contains a set of bedding planes and two other sets of structural planes; their parameters are listed in Table 1.

To choose a proper distribution for each parameter in Table 1, frequency histogram according to the field data should be plotted first. One or several sorts of distributions may be suitable for a parameter, such as normal distribution, log-normal distribution, exponential distribution, and Weibull distribution. In order to determine the most appropriate one, we have taken the hypothetical test for each distribution using the Kolmogorov-Smirnov test method which is shown as Eq. 17, thus to judge whether the distribution would be accepted or not. Finally, combined with the shape of histogram, the most suitable distribution for each parameter can be selected.

$$
D_{\max }=\max _{-\infty<x+\infty}|F(x)-G(x)|<D_{(n, \alpha)} .
$$

According to the equation above, the specific distribution is considered to be acceptable with a certain significance level if $D_{\max }$ - the max numeric difference between the sample distribution function $F(x)$ and the specified distribution function $G(x)$ - is less than $D_{(n, a)}$, which is the critical value with the significance level of $\alpha$, and $n$ is the sample quantity.

An earlier analysis of wedge stability using certain parameters of the structural planes and persistence of $100 \%$ indicated that the larger wedges yield low stability coefficients, as shown by the curve in Fig. 19. However, in this case, the stability coefficients of the wedges with different sizes considering the stochasticity and finite persistence (points in Fig. 19) show different patterns. Although the points are scattered, the stability coefficients first decrease and then increase with increasing wedge size. The points corresponding to the small wedges are near the curve, indicating that the small wedges are less affected by the discontinuities. With increasing wedge size, the stability coefficients increase rather than decrease because of the presence of rock bridges. By fitting an envelope to the lowest bound of all the points, it is concluded that the critical wedge is approximately 2 to 12 meters tall instead of the largest ones, which is consistent with what is frequently observed: wedges that are very large or small are typically stable.

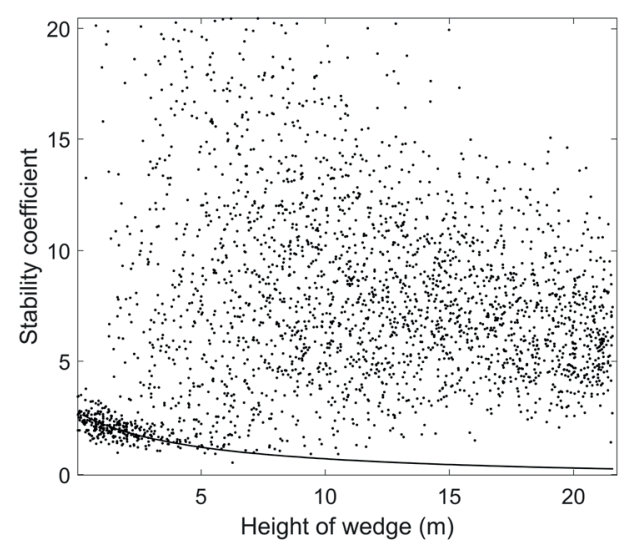

Fig. 19 Stability coefficients of wedges of various heights

Stochastic models of structural plane networks measuring $90 \times 40 \times 32$ meters were built in cases of excavation surface of different length and width, and the failure probabilities in each case were obtained. As shown in Fig. 20, the deeper and longer the excavation, the higher the failure probability. Additionally, with increasing excavation depth, the failure probability increased sharply at first and then reached a steady value. This pattern developed because the wedges exposed first are small ones with a relatively low stability coefficient, followed by the exposing of wedges that are larger and more stable.

In the accident in Chongqing, the wedge failure occurred when the excavation surface was 6.2 meters tall and 70 meters long. According to the results shown in Fig. 20, the failure probability reached $50 \%$. We can also conclude that when the excavation surface was less than 4 meters tall and 10 meters long, its probability of failure was relatively low, and any slope-retaining structures should have been constructed before any subsequent excavation.

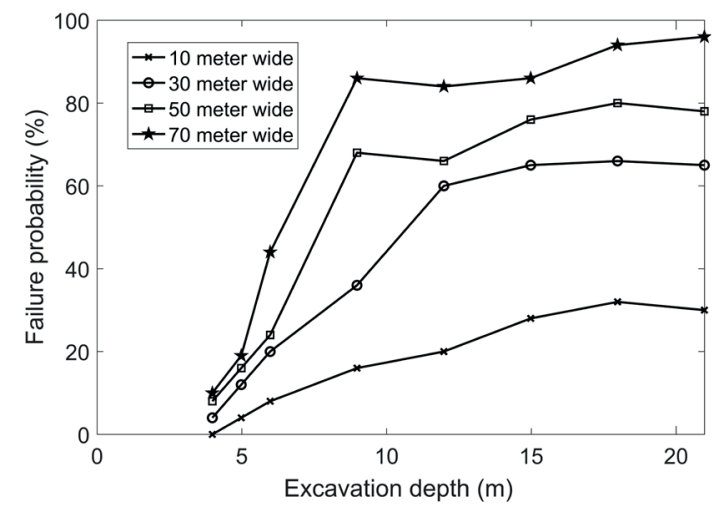

Fig. 20 Probability of rock slope failure with excavation surfaces of various sizes 


\section{Conclusions}

1. BPSO has the advantages of high speed and a simple algorithm, which can improve the processing speed greatly for determining the minimum shear strength combination in $3 \mathrm{D}$ shear zones.

2. The orientation of the shear zone affects the shear strength in rock masses. The shear strength is a minimum when the dip angle and direction of the shear zone are equal to the average dip angle and direction of the structural planes, respectively, and the shear strength is a maximum when these two orientations are orthogonal.

3. The width of the shear zone affects the shear strength in the rock mass. The wider the shear zone, the lower the shear strength, and the shear strength takes on a constant value after the width of the shear zone reaches 2 to 3 times the average structural plane spacing.

4. The length of the shear zone affects the shear strength in the rock mass. Shear strength in short shear zones are typically low. As the length of the shear zone increases, the shear strength increase and finally stabilize after the shear zone reaches a certain length.

5. Generally, with increasing wedge size, the stability coefficient decreases at first and then increases because of the presence of rock bridges.

6. In this case, the deeper and longer the excavation, the higher the failure probability. With increasing excavation depth, the failure probability increases sharply at first and then attains a constant value.

\section{Acknowledgement}

The project presented in this article is supported by the National Natural Science Foundation of China (Nos. 51325903 and 51679017), project 973 (Grant no. 2014CB046903), and the Natural Science Foundation Project CQ CSTC (Nos. CSTC, cstc2015jcyjys30001, cstc2016jcyjys0005 and cstc2015jcyjys30006).

\section{References}

[1] Hoek, E., Bray, J. W. "Rock slope engineering”. Institution of Mining and Metallurgy, London, 1981.

[2] Chen, W. F. "Limit analysis and soil plasticity". Elsevier, Amsterdam, 1975.

[3] Chen, Z. Y. "A generalized solution for tetrahedral rock wedge stability analysis". International Journal of Rock Mechanics \& Mining Sciences, 41(4), pp. 613-628. 2004. 10.1016/j.ijrmms.2003.12.150

[4] Donald, I. B., Chen, Z. Y. "Slope stability analysis by the upper bound approach: fundamentals and methods". Canadian Geotechnical Journal, 34(6), pp. 853-862. 1997. https://doi.org/10.1139/t97-061

[5] Zhou, J. F., Wang, J. X. "Lower bound limit analysis of wedge stability using block element method". Computers and Geotechnics, 86, pp. 120-128. 2017. 10.1016/j.compgeo.2016.12.031

[6] Zhou, X. P., Cheng, H. "Analysis of stability of three-dimensional slopes using the rigorous limit equilibrium method". Engineering Geology, 160, pp. 21-33. 2013. 10.1016/j.enggeo.2013.03.027
[7] Cheng, H., Zhou, X. P. “A novel displacement-based rigorous limit equilibrium method for three-dimensional landslide stability analysis". Canadian Geotechnical Journal, 52(12), pp. 2055-2066. 2015. 10.1139/cgj-2015-0050

[8] Baecher, G. B., Lanney, N. A., Einstein, H. H. "Statistical description of rock properties and sampling". In: The 18th U.S. Symposium on Rock Mechanics (USRMS), 22-24 June, Golden, Colorado, USA. 1977.

[9] Warburton, P. M. "A stereological interpretation of joint trace data". International Journal of Rock Mechanics Sciences, 17(4), pp. 181-190. 1980. 10.1016/0148-9062(80)91084-0

[10] Warburton, P. M. "Stereological interpretation of joint trace data: Influence of joint shape and implication for geological surveys". International Journal of Rock Mechanics and Mining Sciences, 17(6), pp. 305-316. 1980. 10.1016/0148-9062(80)90513-6

[11] Einstein, H. H., Baecher, G. B. "Probabilistic \& statistical method in engineering geology". Rock mechanics and Rock Engineering, 16(1), pp. 39-72. 1983. 10.1007/BF01030217

[12] Long, J. C. S., Gilmour, P., Witherspoon, P. A. “A model for steady fluid flow in random three-dimensional networks of disk shaped fractures". Water Resources Research, 21(8), pp. 1105-1115.1985. 10.1029/WR021i008p01105

[13] Zhan, J., Chen, J., Xu, P., Han, X., Chen, Y. “Computational framework for obtaining volumetric fracture intensity from 3D fracture network models using Delaunay triangulations". Computers and Geotechnics, 89, pp. 179-194. 2017. 10.1016/j.compgeo.2017.05.005

[14] Einstein, H. H., Veneziano, D., Baecher, G. B., O’Reilly, K. J. “The Effect of Discontinuity Persistence on rock slope stability". International Journal of Rock Mechanics and Mining Sciences, 20(5), pp. 227-236. 1983. https:// doi.org/10.1016/0148-9062(83)90003-7

[15] McMahon, B. K. "A statistical method for design of rock slopes". In: Proceedings of the 1st ANZ Conference on Geomechanics, Aug. 9-13, Melbourne, Australia. 1971. pp. 314-321.

[16] McMahon, B. K. "Probability of failure and expect volume of failure in high rock slopes". In: Proceedings of the 2nd Australia-New Zealand Conference on Geomechanics, Brisbane, 1975. pp. 308-313.

[17] Marek, J. M., Savely, J. P. "Probabilistic analysis of plane shear failure mode". In: 19th U.S. Symposium on Rock Mechanics (USRMS), 1-3 May, Reno, Nevada, USA. 1978. p. 6.

[18] Morriss, P., Stotter, H. J. "Open-cut design using probability methods". In: Proc. 5th International Congress on Rock Mechanics, Melbourne, Australia, 1983.

[19] Kim, H. S., Major, G., Brown, D. R. "Application of monte carol techniques to slope stability analysis". In: 19th U.S. Symposium on Rock Mechanics (USRMS), 1-3 May, Reno, Nevada, USA, 1978. p.12.

[20] Herget, G. "Probabilistic slope design for open pit mines". Rock Mechanics, 12, pp. 163-178.1982. 10.1007/978-3-7091-8665-7_12

[21] Li, D. Q., Zhou, C. B., Lu, W. B., Jiang, Q. H. “A system reliability approach for evaluating stability of rock wedges with correlated failure modes". Computers and Geotechnics, 36(8), pp. 1298-1307. 2009. 10.1016/j.compgeo.2009.05.013

[22] Johari, A., Lari, A. M. "System reliability analysis of rock wedge stability considering correlated failure modes using sequential compounding method". International Journal of Rock Mechanics and Mining Sciences, 82(3), pp. 61-70. 2016. 10.1016/j.ijrmms.2015.12.002

[23] Lajtai, E. Z. "Strength of discontinuous rock in direct shear". Geotechnique, 19(2), pp. 218-233. 1969. 10.1680/geot.1969.19.2.218

[24] Lajtai, E. Z. "Shear strength of weakness planes in rock". International Journal of Rock Mechanics \& Mining Sciences \& Geomechanics Abstracts, 6(5), pp. 499-515. 1969. 10.1016/0148-9062(69)90016-3

[25] Shen, B. "The mechanism of fracture coalescence in compression-expression study and numerical simulation". Engineering Fracture Mechanics, 51(1), pp. 73-85.1993. 10.1016/0013-7944(94)00201-R 
[26] Shen, B. T., Stephansson, O. "Numerical analysis of masied model I andmodel II fracture propagation". International Journal of Rock Mechanics \& Mining Sciences \&Geomechanics Abstracts, 30(7), pp. 861-867. 1993. https://doi.org/10.1016/0148-9062(93)90037-E

[27] Shen, B. T., Stephansson, O., Einstein, H. H., Ghahreman, B. "Coalescence of fracture under stresses in experimental". Journal of Geophysical Research Solid Earth, 100(B4), pp. 5975-5990. 1995. 10.1029/95JB00040

[28] Wong, R. H. C., Chau, K. T. "Crack coalescence in a rock-like material containing two cracks". International Journal of Rock Mechanics \& Mining Sciences, 35(2), pp. 147-164. 1998. 10.1016/S0148-9062(97)00303-3

[29] Bobet, A., Einstein, H. H. "Fracture coalescence in rock type material under uniaxial and biaxial compression". International Journal of Rock Mechanics \& Mining Sciences, 35(7), pp. 863-888. 1998. 10.1016/S01489062(98)00005-9

[30] Bobet, A., Einstein, H. H. "Numerical Modeling of Fracture Coalescence in a Model Rock Material". International Journal of Fracture, 92(3), pp. 221-252.1998. 10.1023/A:1007460316400

[31] Vasarhelyi, B., Bobet, A. "Modeling of crack initiation, propagation and coalescence in uniaxial compression". Rock mech\& Rock Engineering, 33(2), pp. 119-139.2000. 10.1007/s006030050038

[32] Xie, Y., Cao, P., Liu, J., Dong, L. "Influence of crack surface friction on crack initiation and propagation: A numerical investigation based on extended finite element method". Computers and Geotechnics, 74, pp. 1-14. 2016. 10.1016/j.compgeo.2015.12.013

[33] Robertson, A. M. "The interpretation of geological factors for use in slope theory". In: Proc. Symposium on the Theoretical Background to the Planning of Open Pit Mines, Johannesburg, South Africa, 1970. https://www. rgc.ca/files/publications/slope_theory.pdf
[34] Meyer, T., Einstein, H. H., Ivanova, V. "Geologic stochastic modeling of fracture systems related to crustal faults". In: Proc. International Congress of the IRSM, 25-28. Aug. Paris, 1, 1999. pp. 493-498.

[35] Hudson, J. A., Priest, S. D. "Discontinuities and rock mass geometry". International Journal of Rock Mechanics \& Mining Sciences \&Geomechanics Abstracts, 16(6), pp. 339-362. 1979. 10.1016/0148-9062(79)90001-9

[36] Priest, S. D., Hudson, J. A. "Discontinuities spacings in rocks". International Journal of Rock Mechanics \& Mining Sciences \&Geomechanics Abstracts, 13(5), pp. 135-148. 1976. 10.1016/0148-9062(76)90818-4

[37] Du, J. C., Wang, X. G., Chen, Z. Y. "Determination of persistence and comprehensive shear strength of jointed rock mass based on waviness created by dip angle variations of discontinuities". Journal of Hydraulic Engineering, 5, pp. 41-46. 2002 .(in Chinese)

[38] Wang, X. G., Chen, Z. Y., Sun, W. S. "Determination of joint persistence and shear strength parameters of rock masses by Monte-Carlo method". Chinese Journal of Rock Mechanics and Engineering, 11(4), pp. 345-355. 1992. (in Chinese)

[39] Eberhart, R. C., Shi, Y. "Particle swarm optimization: developments, application and resources". In: Proceedings of the 2001 Congress on Evolutionary Computation (IEEE Cat. No.01TH8546), Seoul, 2001, pp. 81-86 vol. 1. 2002. 10.1109/CEC.2001.934374

[40] Kennedy, J., Eberhart, R. C. "A discrete binary version of the particle swarm algorithm”.n In: 1997 IEEE International Conference on Systems, Man, and Cybernetics. Computational Cybernetics and Simulation, Orlando, FL, 1997, pp. 4104-4108 vol.5. 1997. 10.1109/ICSMC.1997.637339 